\title{
ELECTROCATALYSIS IN WASTEWATER TREATMENT: RECENT MECHANISM ADVANCES
}

\author{
Carlos A. Martínez-Huitle \\ Departamento de Química, Universidade Federal do Rio Grande do Norte, Campus Universitário - Lagoa Nova, 59072-970 Natal \\ - RN, Brasil \\ Leonardo S. Andrade* \\ Departamento de Química, Universidade Federal de Goiás, Campus de Catalão, Av. Lamartine P. Avelar, 1120, 75704-020 Catalão \\ - GO, Brasil
}

Recebido em 23/9/10; aceito em 4/12/10; publicado na web em 25/3/11

\begin{abstract}
Over 50 years, several scientists and industries have developed new alternatives for wastewater treatment and remediation. Recently, electrochemical technology has been largely developed mainly because of its versatility and environmental compatibility. Scientific contributions about role of the electrode material have allowed determining that the influence of material in the selectivity is an important parameter. However, to interpret this behavior, comprehensive physical chemistry models for organics destruction, related to electrochemical phenomena and material surfaces, were proposed in the last decades. So, this paper presents a critical and comprehensive review about the principles and recent mechanism advances in electrocatalysis for wastewater treatment.
\end{abstract}

Keywords: electrocatalysis; hydroxyl radicals; diamond electrode.

\section{INTRODUCTION}

\section{Environmental electrochemistry}

Electrochemistry can offer much for solving or alleviating environmental problems. Over the past 15 years, electrochemical technology has been largely developed for its alternative use in wastewater remediation. The principal advantage of this technology is its environmental compatibility, due to the fact that it involves the use of a very clean reagent, the electron. Other advantages are related to its versatility, high energy efficiency, amenability to automation, and safety because it is operated at mild conditions. ${ }^{1}$ Of course, it should be emphasized that there are many challenges to be faced in order to achieve high conversion efficiencies. Although the concentrations of pollutants are usually low, it is necessary to consider several possible strategies for particular applications as, for example, the use of suitable electrodes, the promotion of turbulent regimes, preconcentration, use of multistage systems, etc. ${ }^{2}$

\section{Electrochemical oxidation of organic pollutants}

Nowadays, the aquatic environment may be polluted by organic and inorganic chemicals from municipal and industrial sources. Some wastewater pollutants are usually controlled by means of biological treatments. On the other hand, to do so by electrochemistry, the strategies include both the treatment of effluents and waste as well as the development of new processes or products with less harmful effects, often denoted as process-integrated environmental protection. The electrochemistry offers two options for the treatment of these pollutants with the aim of oxidizing them, not only to $\mathrm{CO}_{2}$ and water (known as electrochemical combustion or mineralization), but also to biodegradable products: ${ }^{3}$

- direct anodic oxidation (or direct electron transfer to the anode),

*e-mail: 1s_andrade@ pesquisador.cnpq.br which yields very poor decontamination;

- chemical reaction with electrogenerated species from water discharge at the anode such as physically adsorbed "active oxygen" (physisorbed hydroxyl radical $\left({ }^{\circ} \mathrm{OH}\right)$ ) or chemisorbed "active oxygen" (oxygen in the lattice of a metal oxide (MO) anode). The action of these oxidizing species leads to total or partial decontamination, respectively.

The existence of indirect or mediated electrochemical oxidation (MEO) with different heterogeneous species formed from water discharge has allowed the proposal of two main approaches for the pollution abatement in wastewaters by direct electrochemical oxidation (DEO), which will be described below according the nature of the electrode material.

Nevertheless, the overall performance of electrochemical processes is established by the complex interaction of different parameters that may be optimized to obtain an effective and economical mineralization of pollutants. The principal parameters that determine an electrolysis performance are: electrode potential and current density; current distribution; mass transport regime; cell design; electrolysis medium, and electrode materials. ${ }^{4}$ Even if we still remain far from meeting all the requirements needed for an ideal anode, significant steps have been made toward the production of better electrode materials.

\section{Electrode material}

The ideal electrode material for the degradation of organic pollutants should be totally stable in the electrolysis medium, inexpensive, and highly active towards organic oxidation while lowly active towards secondary reactions (e.g. oxygen evolution reaction - OER). ${ }^{3}$

The nature of the electrode material strongly influences both the selectivity and the efficiency of the process. As a general rule, at satisfactory rates and without electrode deactivation, organics DEO at a given electrode can take place only at high anodic potentials in the 
Table 1. Oxidation power anodes and potential for oxygen evolution of various anode materials in acidic media. Standard potential for oxygen evolution is $1.23 \mathrm{~V}$ vs normal hydrogen electrode. Adapted from refs. 6 and 7

\begin{tabular}{|c|c|c|c|c|}
\hline Electrode & $\begin{array}{l}\text { Oxidation potential } \\
\text { (V) }\end{array}$ & $\begin{array}{c}\text { Overpotential of OER } \\
\text { (V) }\end{array}$ & $\begin{array}{c}\text { Adsorption enthalpy } \\
\text { of } \mathrm{M}-\mathrm{OH}\end{array}$ & $\begin{array}{c}\text { Oxidation power } \\
\text { of anode }\end{array}$ \\
\hline $\begin{array}{l}\mathrm{RuO}_{2}-\mathrm{TiO}_{2} \\
\left(\mathrm{DSA}^{\circledR}-\mathrm{Cl}_{2}\right)\end{array}$ & $1.4-1.7$ & 0.18 & Chemisorption of $\mathrm{OH}$ radical & Lower \\
\hline $\begin{array}{l}\mathrm{IrO}_{2}-\mathrm{Ta}_{2} \mathrm{O}_{5} \\
\left(\mathrm{DSA}^{\circledR}-\mathrm{O}_{2}\right)\end{array}$ & $1.5-1.8$ & 0.25 & & \\
\hline $\mathrm{Ti} / \mathrm{Pt}$ & $1.7-1.9$ & 0.3 & & \\
\hline $\mathrm{Ti} / \mathrm{PbO}_{2}$ & $1.8-2.0$ & 0.5 & & \\
\hline $\mathrm{Ti} / \mathrm{SnO}_{2}-\mathrm{Sb}_{2} \mathrm{O}_{5}$ & $1.9-2.2$ & 0.7 & & \\
\hline $\mathrm{p}-\mathrm{Si} / \mathrm{BDD}$ & $2.2-2.6$ & 1.3 & Physisorption of $\mathrm{OH}$ radical & Higher \\
\hline
\end{tabular}

water discharge region, due to the participation of oxygen evolution intermediates. To interpret this behavior, comprehensive models for organics destruction were proposed in the last decades.

\section{Anodic classification and activity}

As mentioned above, the nature of the electrode material influences the selectivity and the efficiency of an electrochemical process for the oxidation of organic compounds and for this reason, in literature; several anodic materials have been tested in order to find the optimum one.

According to the model proposed by Comninellis, ${ }^{5}$ anode materials are divided for simplicity into two classes: active and non-active electrodes. On the other hand, varying the electrode material makes it possible to form different oxidizing species and thus, modify the oxidation pathway.

Active anodes, which present low oxygen evolution overpotential, are good electrocatalysts for the OER and, consequently, lead to selective oxidation of the organic pollutants. In this way, some electrode materials such as carbon and graphite, platinum-based, iridium-based oxides and ruthenium-based oxides, can be considered into this classification. On the other hand, non-active anodes, which present high oxygen evolution overpotential, are poor electrocatalysts for the OER, and direct electrochemical oxidation is expected to occur for these electrodes. Also, they present no higher oxidation state available and the organic species are directly oxidized by an adsorbed hydroxyl radical, giving complete combustion. So, Antimony-doped tin oxide, Lead dioxide $\left(\mathrm{PbO}_{2}\right)$ and Boron-doped diamond (BDD) are considered non-actives anodes and, therefore, the most suitable for electrochemical combustion reactions.

In order to understand the performance of the anodic materials, Tables 1 and 2 show the typical overpotential values for the OER (in $\mathrm{H}_{2} \mathrm{SO}_{4}$ ) obtained for the most extensively investigated anode materials ${ }^{6}$ and the formation potentials of some typical oxidants, ${ }^{7}$ respectively.

Based on this data, $\mathrm{IrO}_{2}, \mathrm{Pt}$ and graphite show low values of OER overpotential and this is an indicative that anodes with low OER overpotential values (i.e. good catalysts for oxygen evolution reactions) only permit the partial oxidation of organics. But, an effective oxidation of pollutants can be achieved by these electrodes when very low current densities are applied because the OER is disfavored (described in next sections). However, although the oxidation of pollutants is effective at these conditions, the electrolysis time is too long. For the anodes with high OER overpotential (i.e. anodes that are poor catalysts for oxygen evolution reactions), such as $\mathrm{SnO}_{2}, \mathrm{PbO}_{2}$ and $\mathrm{BDD}$, the complete oxidation of organics to $\mathrm{CO}_{2}$ is favored and so are ideal electrodes for wastewater treatment, as it was already pointed previously. This anodic oxidation takes
Table 2. Formation potential of some typical chemical reactants vs. normal hydrogen electrode. Adapted from refs. 6 and 7

\begin{tabular}{llc}
\hline Oxidants & Name & Formation potential \\
\hline $\mathrm{H}_{2} \mathrm{O} / \cdot \mathrm{OH}$ & Hydroxyl radicals & 2.80 \\
$\mathrm{O}_{2} / \mathrm{O}_{3}$ & Ozone & 2.07 \\
$\mathrm{SO}_{4}{ }^{2-} / \mathrm{S}_{2} \mathrm{O}_{8}{ }^{2-}$ & Peroxodisulfate & 2.01 \\
$\mathrm{H}_{2} \mathrm{O} / \mathrm{H}_{2} \mathrm{O}_{2}$ & Hydrogen peroxide & 1.77 \\
$\mathrm{Cl}^{-} / \mathrm{ClO}_{2}^{-}$ & Chlorine dioxide & 1.57 \\
$\mathrm{Cl}^{-} / \mathrm{Cl}_{2}$ & Chlorine & 1.36 \\
$\mathrm{H}_{2} \mathrm{O} / \mathrm{O}_{2}$ & Oxygen & 1.23 \\
\hline
\end{tabular}

place on its surface at significant high current density with minimal amount of oxygen evolution side reaction, giving an efficient and effective process. ${ }^{3,5,6}$

However, although $\mathrm{SnO}_{2}$ and $\mathrm{BDD}$ anodes represent attractive and efficient materials for the degradation of refractory pollutants, $3,5,6$ their industrial application for water treatment may be limited by specific features. For example, in the case of $\mathrm{SnO}_{2}$ anodes the main inconvenient is related with their short service-life, while for BDD electrodes the unacceptably high cost production and fragility are considered the limiting for industrial applications. To remark this behavior, the characteristics of DEO and its relevant application to organic pollutants removal will be illustrated considering some examples, which were summarized in Table 3 .

An inspection of Table 3 corroborates the great mineralization attained for several pollutants in DEO with different anode materials. Also, in order to demonstrate the potential application of this process for treating wastewaters as well as the influence the reactivity towards organic oxidation caused by the use of different electrode materials, other results obtained by DEO also has been recently reviewed and described in detail by other authors such as Panizza and Cerisola, ${ }^{8}$ Brillas et al., ${ }^{9}$ Martínez-Huitle and Brillas ${ }^{10}$ and Martínez-Huitle and Ferro. ${ }^{3}$

\section{ORGANIC OXIDATION MECHANISM}

In early studies, a mechanism for oxidizing organic pollutants was proposed by Feng and Johnson, ${ }^{33}$ based on MEO at a high potential via the intermediates of the oxygen evolution reaction (OER). This process involves the transfer of anodic oxygen from $\mathrm{H}_{2} \mathrm{O}$ to the organics via adsorbed hydroxyl radicals generated by the water discharge:

$$
\begin{gathered}
\mathrm{S}[]+\mathrm{H}_{2} \mathrm{O} \rightarrow \mathrm{S}\left[{ }^{\bullet} \mathrm{OH}\right]+\mathrm{H}^{+}+\mathrm{e}^{-} \\
\mathrm{S}\left[{ }^{\circ} \mathrm{OH}\right]+\mathrm{R} \rightarrow \mathrm{S}[]+\mathrm{RO}+\mathrm{H}^{+}+\mathrm{e}^{-}
\end{gathered}
$$


Table 3. Percentage of elimination and energy consumption for the electrochemical oxidation with metal oxides, Pt, carbonaceous and BDD anodes of selected solutions. Adapted from ref. 10

\begin{tabular}{|c|c|c|c|c|c|c|c|}
\hline Dye $^{a}$ & $\begin{array}{c}C_{0} \\
/ \mathrm{mg} \mathrm{dm}^{-3} \\
\end{array}$ & $\begin{array}{c}j^{\mathrm{b}} \\
/ \mathrm{mA} \mathrm{cm}^{-2}\end{array}$ & $\begin{array}{c}\text { Electrolysis } \\
\text { time / h }\end{array}$ & $\begin{array}{c}\text { Color } \\
\text { removal / \% }\end{array}$ & $\begin{array}{c}\mathrm{COD} \\
\text { decay } / \% \\
\end{array}$ & Energy consumption $^{\mathrm{c}}$ & Ref \\
\hline $\begin{array}{l}\mathrm{PbO}_{2} \text { anode } \\
\text { Blue Reactive } 19\end{array}$ & 25 & 50 & 2 & 100 & $95 \mathrm{~d}$ & $\begin{array}{l}1.86 \mathrm{kWh} \mathrm{m}^{-3} \text { for pure } \\
\text { electrode and } 1.66 \\
\mathrm{kWh} \mathrm{m}^{-3} \text { for Fe,F- } \\
\text { doped electrode at } \\
90 \% \text { decolorization }\end{array}$ & 11 \\
\hline Basic Brown 4 & 100 & 30 & 0.5 & 100 & 73 & $\mathrm{e}$ & 12 \\
\hline Acid Red 2 (Methyl Red) & $235 f$ & 31.2 & 11 & 100 & 97 & $\mathrm{e}$ & 12 \\
\hline \multicolumn{8}{|l|}{$\mathrm{Ti} / \mathrm{Sb}_{2} \mathrm{O}_{5}-\mathrm{SnO}_{2}$ anode } \\
\hline Acid Orange 7 (Orange II) & 750 & 20 & $6.25 \mathrm{~h}$ & 98 & 27 & e & 14 \\
\hline $\begin{array}{l}\text { Reactive Red } 120 \\
\text { (Reactive Red HE-3B) }\end{array}$ & 1500 & 20 & $6.25 \mathrm{~h}$ & 95 & 13 & $\mathrm{e}$ & 15 \\
\hline
\end{tabular}

\begin{tabular}{|c|c|c|c|c|c|c|c|}
\hline \multicolumn{8}{|l|}{$\mathrm{Ti} / \mathrm{Ru}_{0.3} \mathrm{Ti}_{0.7} \mathrm{O}_{2}$ anode } \\
\hline Reactive Red 198 & 30 & 50 & 3 & 80 & $18 \mathrm{~d}$ & $95 \times 10^{6} \mathrm{kWh} \mathrm{kg}$ dye $\mathrm{e}^{-1}$ & 16 \\
\hline Direct Red 81 & $0.1-1$ & 25 & 3 & 100 & $57-61^{\mathrm{d}}$ & $0.555 \mathrm{kWh}(\mathrm{g} \text { TOC })^{-1}$ & 17 \\
\hline Direct Black 36 & $\mathrm{~g}$ & 25 & 3 & 40 & Od & $\mathrm{e}$ & 17 \\
\hline \multicolumn{8}{|l|}{ Pt anode } \\
\hline Acid Red 27 (Amaranth) & 100 & $10-20$ & 3 & 100 & 10 & $\mathrm{e}$ & 18 \\
\hline $\begin{array}{l}\text { Reactive } \\
\text { Orange } 4\end{array}$ & 100 & 40 & 1 & 91 & $\mathrm{e}$ & $44.1 \mathrm{kWh} \mathrm{m}^{-3}$ & 19 \\
\hline
\end{tabular}

\begin{tabular}{|c|c|c|c|c|c|c|c|}
\hline \multicolumn{8}{|l|}{ Activated carbon anode fiber } \\
\hline Acid Red 27 (Amaranth) & 80 & 0.5 & 8 & 99 & 52 & $\mathrm{e}$ & 20 \\
\hline \multicolumn{8}{|l|}{ Graphite anode } \\
\hline Vat Blue 1 (Indigo) & 200 & 0.43 & 0.5 & 14 & $\mathrm{e}$ & $6.93 \mathrm{kWh} \mathrm{m}^{-3}$ & 21 \\
\hline \multicolumn{8}{|l|}{ Ti/BDD anode } \\
\hline Acid Orange 7 (Orange II) & 750 & 20 & $6.25^{\mathrm{d}}$ & 90 & 92 & $\mathrm{e}$ & 14 \\
\hline 15 reactive dyes & 1000 & 10 & $2-4^{\mathrm{d}}$ & $>95$ & $89-95$ & 8.9-17.9 $\mathrm{kWh} \mathrm{m}^{-3}$ & 22 \\
\hline \multicolumn{8}{|l|}{$\mathrm{Nb} / \mathrm{BDD}$ anode } \\
\hline Blue Reactive 19 & 25 & 50 & $0.3^{\mathrm{d}}$ & 95 & $82^{f}$ & $\mathrm{e}$ & 11 \\
\hline Basic Red 29 & 40 & 1 & 0.03 & 98 & $\mathrm{e}$ & $\mathrm{e}$ & 23 \\
\hline Textile wastewater & $566^{\mathrm{g}}$ & 1 & 8.5 & 97 & 92 & $1.4 \mathrm{kWh}(\mathrm{g} \mathrm{COD})^{-1}$ & 23 \\
\hline \multicolumn{8}{|l|}{$\mathrm{Si} / \mathrm{BDD}$ anode } \\
\hline Acid Red 27 (Amaranth) & 100 & 80 & 6.5 & 100 & $100,94^{\mathrm{f}}$ & e & 18 \\
\hline Acid Orange 7 (Orange II) & $0.1^{\mathrm{h}}$ & 20 & 2.5 & 100 & 100 & $\mathrm{e}$ & 24 \\
\hline Acid Red 2 (Methyl Red) & 200 & 31.2 & 100 & 6 & 98 & e & 13 \\
\hline Vat Blue 1 (Indigo) & $0.29^{\mathrm{h}}$ & $0.36-80$ & 9.5 & 100 & e & $0.47-35 \mathrm{kWh} \mathrm{m}^{-3}$ & 25 \\
\hline Mordant Black 11 (Eriochrome Black T) & $100^{\mathrm{g}}$ & 30 & 4 & 100 & $100,100 f$ & $800 \mathrm{kWh} \mathrm{m}^{-3}$ & 26 \\
\hline Acid Blue 22 & $0.3^{\mathrm{h}}$ & 20 & 12 & 100 & 97 & $70 \mathrm{kWh} \mathrm{m}^{-3}$ & 27 \\
\hline Acid black 210 & 500 & 5 & 25 & 100 & 100 & $53 \mathrm{kWh} \mathrm{m}^{-3}$ & 28 \\
\hline \multicolumn{8}{|l|}{ BDD with supports unspecified } \\
\hline Blue Reactive 19 & 50 & 50 & 2 & 100 & 100 & $\mathrm{e}$ & 29 \\
\hline Direct Red 80 & 350 & 1.5 & 24 & 100 & 87 & $6.65 \mathrm{kWh} \mathrm{m}^{-3}$ & 30 \\
\hline 5 textile dyes & 500 & 2.5 & 2 & $50-80$ & $60-80$ & $\mathrm{e}$ & 31 \\
\hline Acid Orange 7 & 360 & 10 & 8 & 100 & 90 & $\mathrm{e}$ & 32 \\
\hline
\end{tabular}

${ }^{\mathrm{a}}$ Color Index (common) name; ${ }^{\mathrm{b}}$ Applied current density; ${ }^{\mathrm{c}}$ Different units reported; ${ }^{\mathrm{d}}$ Percentage of TOC decay; ${ }^{\mathrm{e}}$ Not determined; ${ }^{\mathrm{f}}$ Initial COD; ${ }^{\mathrm{g}} \mathrm{mM}$ concentra-

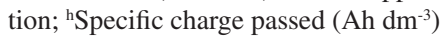

where S[ ] represents the surface sites where the ${ }^{\circ} \mathrm{OH}$ species can be adsorbed. Concomitantly, an inevitable and undesirable event takes place, the OER due to the oxidation of water:

$$
\mathrm{S}[\cdot \mathrm{OH}]+\mathrm{H}_{2} \mathrm{O} \rightarrow \mathrm{S}[]+\mathrm{O}_{2}+3 \mathrm{H}^{+}+3 \mathrm{e}^{-}
$$

Later, Comninellis ${ }^{5}$ elucidated the mechanism of the electrochemical conversion/combustion of organics, with simultaneous oxygen evolution, using different anode materials $\left(\mathrm{Pt}, \mathrm{Ti} / \mathrm{IrO}_{2}\right.$ and $\mathrm{Ti} / \mathrm{SnO}_{2}$ ). According to such mechanism, selective oxidation of organics occurs at electrodes on which the so-called higher oxide lattice can be formed, $\mathrm{MO}_{\mathrm{x}+1}$, (chemisorbed "active oxygen") whereas combustion occurs at electrodes at whose surface ${ }^{\circ} \mathrm{OH}$ radicals are accumulated (physisorbed "active oxygen"). The detection of $\cdot \mathrm{OH}$ radicals formed by water discharge at different anodes using spin trapping was demonstrated during these experiments. This showed that at the surface of $\mathrm{Pt}$ and $\mathrm{IrO}_{2}$ anodes the ${ }^{\circ} \mathrm{OH}$ radical concentration was almost zero, while at the surface of a $\mathrm{SnO}_{2}$ anode there was a much higher accumulation of ${ }^{\circ} \mathrm{OH}$ radicals. Thus, according to the proposed mechanism, the $\mathrm{SnO}_{2}$ anode favors organics 
complete combustion whereas the $\mathrm{IrO}_{2}$ and $\mathrm{Pt}$ anodes favor organics selective oxidation.

\section{Model for organics oxidation with heterogeneous hydroxyl radical}

Advances in materials science have led to a whole range of new materials that find applications in environmental electrochemistry due to special features that improve their catalytic properties for electrochemical reactions. An innovative electrode for this type of applications was introduced in the end of the 1990's. This is the borondoped diamond (BDD) electrode, which is characterized by high reactivity towards organics oxidation and efficient use of electrical energy. BDD is a typical high oxidation power anode (Table 1). In fact, by electron spin resonance measurements using spin traps, the formation of quasi-free hydroxyl radicals on the BDD surface was demonstrated. These electrogenerated hydroxyl radicals on the BDD anode are very reactive (owing to a weak BDD-hydroxyl radical interaction) and thus can lead to the organics combustion with a high current efficiency. These results allowed the initial mechanism for DEO proposed by Comninellis to become ultimate, because its predictions fit quite well with results obtained with BDD anodes and make possible the generation of a classification of the different anode materials according to their oxidation power in acid media. Comninellis and co-workers ${ }^{34}$ explained the different behavior of electrodes in electrochemical oxidation (EO) considering two limiting cases: the so-called "active" and "non-active" anodes. $\mathrm{Pt}, \mathrm{IrO}_{2}$, and $\mathrm{RuO}_{2}$ are typical examples of the former and $\mathrm{PbO}_{2}, \mathrm{SnO}_{2}$, and $\mathrm{BDD}$ of the latter. The complete proposed model assumes that the initial reaction in both anode types (generically denoted as $\mathrm{M}$ ) corresponds to the oxidation of water molecules leading to the formation of physisorbed hydroxyl radical $\left(\mathrm{M}\left({ }^{\circ} \mathrm{OH}\right)\right)$ :

$$
\mathrm{M}+\mathrm{H}_{2} \mathrm{O} \rightarrow \mathrm{M}\left({ }^{\circ} \mathrm{OH}\right)+\mathrm{H}^{+}+\mathrm{e}^{-}
$$

Both the electrochemical and the chemical reactivity of heterogeneous $\mathrm{M}\left({ }^{\circ} \mathrm{OH}\right)$ are dependent on the nature of the electrode material. The surface of active anodes interacts strongly with ${ }^{\circ} \mathrm{OH}$ and thus a so-called higher oxide or superoxide (MO) may be formed according to reaction 5 . This may occur when higher oxidation states are available for a metal oxide anode, above the standard potential for oxygen evolution.

$$
\mathrm{M}\left({ }^{\circ} \mathrm{OH}\right) \rightarrow \mathrm{MO}+\mathrm{H}^{+}+\mathrm{e}^{-}
$$

The redox couple MO/M acts as a mediator in the organics oxidation according to reaction 6 , which competes with the OER, a side reaction, via the chemical decomposition of the higher oxide species, as shown in reaction 7 .

$$
\begin{gathered}
\mathrm{MO}+\mathrm{R} \rightarrow \mathrm{M}+\mathrm{RO} \\
\mathrm{MO} \rightarrow \mathrm{M}+1 / 2 \mathrm{O}_{2}
\end{gathered}
$$

In contrast, the surface of a non-active anode interacts so weakly with ${ }^{\circ} \mathrm{OH}$ that it allows the direct reaction of the organics with $\mathrm{M}\left({ }^{\circ} \mathrm{OH}\right)$ to yield fully oxidized reaction products such as $\mathrm{CO}_{2}$, as follows:

$$
a \mathrm{M}\left({ }^{\circ} \mathrm{OH}\right)+\mathrm{R} \rightarrow \mathrm{M}+m \mathrm{CO}_{2}+n \mathrm{H}_{2} \mathrm{O}+x \mathrm{H}^{+}+y \mathrm{e}^{-}
$$

where $\mathrm{R}$ is an organic compound with $m$ carbon atoms and without any heteroatom, which needs $a(=2 m+n)$ oxygen atoms to be totally mineralized to $\mathrm{CO}_{2}$. The oxidative reaction 6 involving the surface redox couple $\mathrm{MO} / \mathrm{M}$ is much more selective than the mineralization reaction 8 involving the physisorbed heterogeneous hydroxyl radical. The latter reaction also competes with the side reactions of $\mathrm{M}(\bullet \mathrm{OH})$, such as the direct oxidation to $\mathrm{O}_{2}$ (reaction 9) or the indirect consumption through dimerization to hydrogen peroxide (reaction 10):

$$
\begin{gathered}
\mathrm{M}\left({ }^{\circ} \mathrm{OH}\right) \rightarrow \mathrm{M}+1 / 2 \mathrm{O}_{2}+\mathrm{H}^{+}+\mathrm{e}^{-} \\
2 \mathrm{M}\left({ }^{\circ} \mathrm{OH}\right) \rightarrow 2 \mathrm{M}+\mathrm{H}_{2} \mathrm{O}_{2}
\end{gathered}
$$

A non-active electrode does not participate in the direct anodic reaction of organics and does not provide any catalytic active site for their adsorption from aqueous media. It only acts as an inert substrate and as a sink for the removal of electrons. In principle, only outersphere reactions and water oxidation are possible with this kind of anode. Hydroxyl radicals produced from water discharge by reaction 4 are subsequently involved in the organics oxidation process. The above model presupposes that the electrochemical activity and the chemical reactivity of physisorbed $\mathrm{M}\left({ }^{\circ} \mathrm{OH}\right)$ are strongly linked to the strength of the $\mathrm{M}-{ }^{-} \mathrm{OH}$ interaction (see also Table 1). Therefore, the BDD anode is the best non-active electrode that presents this behavior, ${ }^{3-8}$ thus being proposed as the preferable anode for the treatment of organics by electrochemical oxidation.

\section{Kinetic model of organics mineralization on BDD anodes}

In order to describe experimental results according to the model for organics EO, Comninellis and co-workers ${ }^{35}$ developed a comprehensive kinetic model that allowed them to predict the trend of the chemical oxygen demand (COD) and the instantaneous current efficiency (ICE) for organics EO using BDD electrodes. The anodic oxidation of organics was assumed to be a fast reaction and the oxidation of organics in the bulk of the electrolyte, by means of electrogenerated oxidants, was not considered. The formulation of the model starts with the estimation of the limiting current density, from COD values:

$$
i_{\lim (t)}=4 F k_{m} \operatorname{COD}_{(t)}
$$

where $\mathrm{i}_{\lim (t)}$ is the limiting current density $\left(\mathrm{A} \mathrm{m}^{-2}\right)$ at a given time $t$, 4 is the number of exchanged electrons, $F$ is the Faraday constant $\left(\mathrm{C} \mathrm{mol}{ }^{-1}\right), k_{m}$ the mass-transport coefficient in the electrochemical reactor $\left(\mathrm{m} \mathrm{s}^{-1}\right)$, and $\operatorname{COD}_{(t)}$ the chemical oxygen demand $\left(\mathrm{mol} \mathrm{m}^{-3}\right)$ at the given time $t$.

Depending on the applied current density, two different operating regimes can be identified: $i_{\text {appl }}<i_{\text {lim }}$ : the electrolysis is under current control, the current efficiency is $100 \%$, and the COD decreases linearly with time; $i_{\text {appl }}>i_{\text {lim }}$ : the electrolysis is under mass-transport control, secondary reactions (such as the OER) are involved, resulting in an ICE decrease. Under these conditions, the COD removal, due to mass-transport limitations, follows an exponential trend. From the COD mass-balances of the electrochemical reactor and the reservoir, the equations that describe the temporal evolution of COD and ICE can be obtained. However, in various cases the experimental ICE values were higher than $100 \%$ under optimal electrolysis regime conditions at BDD anodes, ${ }^{36}$ as shown in Figure 1. This experimental observation did not influence the predictions of this kinetic model; however, it called the attention of several electrochemistry research groups.

Polcaro and co-authors reported a more complex model with the aim of evaluating the trends of the concentrations of the starting pollutant and intermediate products in thestagnant layer and in the bulk. ${ }^{37}$ Thus, it has been shown that the incineration of some organics 


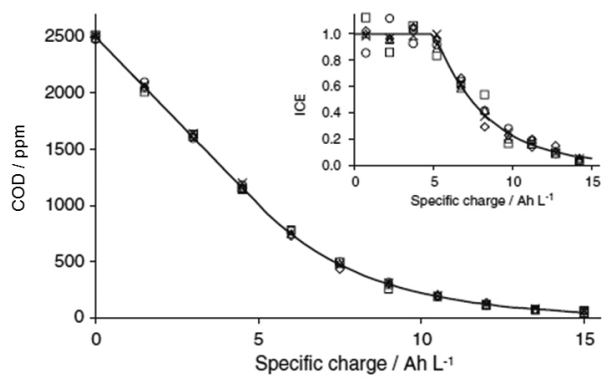

Figure 1. Experimental (symbols) and predicted (solid line) results for COD and ICE (inset) evolution as a function of specific charge during various organics mineralization on a BDD anode $\left(i=238 \mathrm{~A} \mathrm{~m}^{-2}, T=298 \mathrm{~K}\right.$, in $1 \mathrm{~mol}$ $\left.L^{-1} \mathrm{H}_{2} \mathrm{SO}_{4}\right)$ : $(\times)$ acetic acid; $(\diamond)$ isopropanol; ( $($ ) phenol; ( $\square)$ 4-chlorophenol; (•) 2-naphthol. Adapted from ref. 36

at BDD proceeds through the formation of some intermediates. As an example, the oxidation of phenol can be represented by the following schematic reaction path:

Phenol $\rightarrow$ Cyclic intermediates $\rightarrow$ Aliphatic acids $\rightarrow \mathrm{CO}_{2}$

Furthermore, this model applies also to the case of an oxidation process that gives rise to a current efficiency lower than $100 \%$ in the absence of mass transfer limitations. The model was based on the following assumptions:

- oxidation of pollutants and intermediate compounds takes place by homogeneous chemical reaction with hydroxyl radicals (with first order kinetic with respect to both organics and hydroxyl radicals concentrations) in the diffusion layer in competition with the chemical deactivation of hydroxyl radicals which is described by a first order kinetic reaction not depending on the working potential;

- a diffusion-reaction model is used to model the diffusion layer while the bulk of the solution is represented by a stirred-tank reactor.

By a numerical solution of pertaining equations (mass balance equations in the bulk and in the stagnant layer for the starting pollutant and intermediates and in the diffusion layer for hydroxyl radicals), authors were able to predict the trend with time of the different compounds present in the bulk of the solution during the electrolyses, as well as the evolution of the space profile of the species.

As an example, Polcaro et al. ${ }^{37}$ used their model to predict with a good accuracy, for the oxidation of phenol, the trend with time of the concentrations of phenol and main intermediates (aromatic and aliphatic acids) by changing significantly the current density and the flow dynamic regime and using only one adjustable parameter (the average kinetic constant between hydroxyl radicals and aromatic compounds). A good agreement between theoretical predictions and experimental data was also reported by these authors in the cases of cyanuric acid and atrazine by using this model as an adjustable parameter to the kinetic constant between hydroxyl radicals and the adopted pollutant. As above mentioned, the model involved also the calculation of the concentration profiles in the diffusion layer of hydroxyl radicals, pollutants and intermediates with the time. Quite interestingly, according to this model, hydroxyl radicals diffuse in the stagnant layer for few tens of nanometers in agreement with literature.

In order to reduce the mathematically complexity of theoretical models aimed to determine the concentrations of compounds involved in the oxidation process, Cañizares et al. ${ }^{38-40}$ considered some simplifying assumptions. Their model divides the electrochemical reactor into three zones: two close to the electrodes (electrochemical zones) and a third zone corresponding to the bulk of the solution (chemical zone) that can be considered as consecutive stirred-tank reactors. Hence, in each zone, the concentration is assumed to depend on the time passed, but not on the position. The concentration of each compound in the chemical zone is taken as the value measured experimentally. Mass transport processes between the electrochemical and chemical zones are quantified by assuming that the local exchange rate is proportional to the difference of concentration between the two zones. They observed that a number of processes can occur at the electrode surface, and therefore, the total current applied is shared among all these processes. The rate of each process is given by

$$
r_{\mathrm{i}}=\left(i_{\text {app }} \mathrm{A} / \mathrm{F}\right) \alpha_{i}^{\text {electrode }}
$$

where $\alpha_{i}^{\text {electrode }}$, that gives the ratio of current density for a particular electrochemical process with respect to the applied current density, is a measure of the relative oxidizability of a compound, such that $\Sigma \alpha_{i}^{\text {electrode }}=1$. In a first version of the model, $\alpha_{i}^{\text {electrode }}$ were a function of the oxidizability factors of the compounds in the electrochemical system, which were computed as adjustable parameters. ${ }^{37}$ Later authors assumed that the fraction of $i_{\text {app }}$ used in each process depends on the cell potential $\left(\Delta \mathrm{V}_{\text {work }}\right)$ and the oxidation (or reduction) potential $\left(\Delta \mathrm{V}_{\mathrm{i}}\right)$ of each process by the relationship reported below, so that no adjustable parameters were used in the model. ${ }^{39}$

$$
\alpha_{\mathrm{i}}^{\text {electrode }}=\left(\Delta \mathrm{V}_{\text {work }}-\Delta \mathrm{V}_{\mathrm{i}}\right) / \Sigma\left(\Delta \mathrm{V}_{\text {work }}-\Delta \mathrm{V}_{\mathrm{i}}\right)
$$

The model accounted also for the presence of homogeneous oxidation reactions between electrogenerated oxidants and organics, assuming second-order rate expressions depending on the concentrations of both the oxidant and the organic compound.

In the case of phenol and carboxylic acids, no presence in the bulk of oxidants was evaluated with a $\mathrm{I}_{2} / \mathrm{I}^{-}$test. ${ }^{39} \mathrm{It}$ was, therefore, concluded that no mediated oxidation processes occurred in the bulk zone. Hence, mediated process, involving oxidation by means of hydroxyl radicals, might occur only in the electrochemical zone and were considered as direct reactions. The model showed a good agreement with a very large set of experimental data obtained for the incineration of various organic compounds including phenol and different carboxylic acids at BDD in a water solution of $\mathrm{Na}_{2} \mathrm{SO}_{4}{ }^{39} \mathrm{In}$ the case of phenol, as an example, the model considered the direct oxidation of phenol at the anode to carbon dioxide, via the formation of maleic and oxalic acids as intermediates, and the hydrogen evolution at the cathode and the predicted profile concentrations of phenol, maleic and formic acids with the charge passed were in a good agreement with experimental data obtained under a very large range of operative conditions.

Finally, other model have recently published where the effect of operative parameters on the performances of the process was recently investigated by Scialdone et al. ${ }^{41-44}$ by considering, for the sake of simplicity, the complete oxidation of an organic pollutant that proceed in competition with the oxygen evolution with no formation of intermediates with significant concentrations in the bulk. In this case, the instantaneous current efficiency for a process under galvanostatic mode can be rapidly estimated for both mass transfer and oxidation reaction control regimes. A good agreement between experimental data and theoretical predictions was observed changing severely the current density, the flow rate and the initial concentration of the carboxylic acids tested. Please note that numerous kinetic oxidation models were studied by various groups, including those of Comninellis, Polcaro, Rodrigo and Scialdone with different approaches. 
However, the best fit experimental-theoretical data was obtained by Comninellis $^{35}$ for EO industrial application.

\section{Electrical energy consumption in the electrochemical mineralization process}

In contrast to the chemical oxidation process in which strong oxidants (usually in the presence of catalysts) are used in order to achieve efficient treatment, the electrochemical process consumes mainly electrical energy. The specific energy consumption for the electrochemical treatment of a given wastewater can be estimated from the relation: ${ }^{36}$

$$
E=\frac{4 F V_{c}}{3600 E O I} \quad \text { with } 0 \leq \mathrm{EOI} \leq 1
$$

where $E$ is the specific energy consumption (kWh / kmol COD), $F$ is Faraday's constant $\left(\mathrm{C} / \mathrm{mol}\right.$,) $V_{c}$ is the cell potential (V) and EOI is the electrochemical oxidation index (which represents the average current efficiency for organics oxidation) and given by:

$$
E O I=\frac{\int_{0}^{\tau} I C E d t}{\tau} \quad \text { with } 0 \leq \mathrm{EOI} \leq 1
$$

where ICE is the instantaneous current efficiency and $\tau$ is the duration of the electrochemical treatment (s). Using the numerical values, equation can be written as:

$$
E=107.2 \frac{V_{c}}{E O I} \quad \text { with } 0 \leq \mathrm{EOI} \leq 1
$$

The cell potential can be related to the current density by the relation: $\mathrm{V}_{\mathrm{c}}=\mathrm{V}_{0}+\rho d i$ where $\mathrm{V}_{0}$ is the constant depending on the nature of the electrolyte $(\mathrm{V}), \rho$ is the resistivity of the electrolyte $(\mathrm{W} \mathrm{m}), d$ is the inter-electrode distance $(\mathrm{m})$ and $i$ is the current density $\left(\mathrm{A} \mathrm{m}^{-2}\right)$. Combining equations gives:

$$
E=107.2 \frac{\left(V_{0}+\rho d i\right)}{E O I} \quad \text { with } 0 \leq \mathrm{EOI} \leq 1
$$

This relation shows that the specific energy consumption decreases with increasing average current efficiency, reaching a minimum value at $\mathrm{EOI}=1$. As shown in the previous section, the specific energy consumption for the electrochemical mineralization of organics decreases strongly with increasing average current efficiency (EOI) and reaches a minimum value at $\mathrm{EOI}=1$. In order to work under these favorable conditions (at which EOI $=1$ ), electrolysis has to be carried out under programmed current, in which the current density during electrolysis is adjusted to the limiting value.

\section{RECENT MECHANISM ADVANCES}

\section{Formation and reactivity of free hydroxyl radicals on boron- doped diamond electrodes}

The formation and reactivity of free hydroxyl radicals depends on the nature of electrode material, as demonstrated by Comninellis in 1994. ${ }^{5}$ Nevertheless, when BDD was employed as anode material, a peculiarity of this electrode was its higher production of hydroxyl radicals and the reactivity of these hydroxyl radicals; than other electrocatalytic materials. The experimental evidence for formation of hydroxyl radicals on BDD electrode was given by Marselli et al. ${ }^{34}$ during electrolysis in $1 \mathrm{M} \mathrm{HClO}_{4}$. The authors detected $\mathrm{HO} \bullet$ by means of spin trapping, using electron spin resonance; concluding that electrogenerated hydroxyl radicals are very reactive and in the absence of organic compounds can react with each other to form hydrogen peroxide which is further oxidized to $\mathrm{O}_{2}$. Indeed, hydrogen peroxide was detected on BDD during electrolysis of $1 \mathrm{M} \mathrm{HClO}_{4} \cdot{ }^{45,46}$ In the presence of organic compound, hydroxyl radicals are involved in organics oxidation (indirect oxidation), as it has been proposed by Feng and Johnson. ${ }^{33}$ Therefore, recent studies have been performed using BDD anodes in order to understand better the mechanisms, kinetic and hydroxyl radicals which mediate the oxidation processes in the vicinity of the electrode surface. ${ }^{46}$

In this frame, a model describing the hydroxyl radical concentration profile at the interface of $\mathrm{BDD}$, in the presence and absence of organic compounds, was reported by Comninellis and co-workers. ${ }^{46}$ The determined surface concentration of $\mathrm{HO} \bullet$ was related with the shift of the current-potential curves (toward lower potentials) induced by the reaction of the electrogenerated $\mathrm{HO} \bullet$ with the organic compounds present in the electrolyte. The experimental verification of the proposed model was tested using methanol and formic acid as model organic compounds.

\section{Concentration profile of $\mathrm{HO}^{*}$ during oxygen evolution ${ }^{46}$}

They have considered that in the absence of organic compounds, electrogenerated free hydroxyl radicals can react with each other to form hydrogen peroxide, as given by the following equation:

$$
\mathrm{HO}^{*}+\mathrm{HO}^{*} \rightarrow \mathrm{H}_{2} \mathrm{O}_{2}
$$

Hydrogen peroxide can be further oxidized to oxygen either by its direct discharge on the electrode surface (Equation 19) or via assistance of hydroxyl radicals (Equation 20):

$$
\begin{gathered}
\mathrm{H}_{2} \mathrm{O}_{2} \rightarrow \mathrm{O}_{2}+2 \mathrm{H}^{+}+2 \mathrm{e}^{-} \\
\mathrm{H}_{2} \mathrm{O}_{2}+2 \mathrm{HO}^{\cdot} \rightarrow \mathrm{O}_{2}+2 \mathrm{H}_{2} \mathrm{O}
\end{gathered}
$$

Assuming that the first step (Equation 18) is the rate determining step and that four hydroxyl radicals (four electrons) are needed for oxygen evolution. Then, the mass balance for hydroxyl radicals was considered by authors, by applying one-dimensional Fick law referred to the molecular diffusion in a stagnant layer and considering the diffusion coefficient of $\mathrm{HO}^{*}$, the rate constant of reaction $18 \mathrm{k}_{\mathrm{HO}} \cdot\left(\mathrm{m}^{3}\right.$ $\mathrm{mol}^{-1} \mathrm{~s}^{-1}$ ) and the concentration of $\mathrm{HO}^{\circ}$ as well as, assuming that far from the electrode $(\mathrm{x}=\infty)$ concentration of hydroxyl radicals is 0 , whereas at the electrode $(x=0)$ there is a surface concentration of hydroxyl radicals; the concentration profile of hydroxyl radicals, as a function of the distance $\mathrm{x}$ from the electrode surface during oxygen evolution was determined by them.

Thus, the flux of hydroxyl radicals at the electrode surface was expressed in terms of the current density $\mathrm{j}$, allowing the determination of the concentration profile of hydroxyl radicals during oxygen evolution as a function of the distance from the electrode surface. From these results, at current density $\left(j=300 \mathrm{~A} \mathrm{~m}^{-2}\right)$, the reaction layer thickness is about $1 \mu \mathrm{m}$ whereas the maximum (surface) concentration of hydroxyl radicals reaches the value of several tenths of $\mu \mathrm{M}$.

\section{Concentration profile of $\mathrm{HO}^{*}$ during oxidation of organics ${ }^{46}$}

In this case, by analogous mathematical treatment in absence of organic pollutants, it is possible to determine the concentration profile of hydroxyl radicals during oxidation of organic compounds. However, the authors have considered important hypotheses: 
- oxidation of organic compounds $\mathrm{R}$ proceeds only via assistance of hydroxyl radicals in the vicinity of the electrode surface:

$$
\mathrm{R}+z \mathrm{HO} \bullet \rightarrow \text { oxidation products }
$$

- concentration of organic compound is high enough to be considered as a constant in the reaction layer;

- oxygen evolution, via $\mathrm{H}_{2} \mathrm{O}_{2}$ oxidation, is negligible.

Then, in the presence of organic compound, concentration of hydroxyl radicals decreases exponentially with the distance from the electrode surface. The thickness of the reaction layer (reaction cage) depends on the concentration of organic compound, the rate constant of organics oxidation (via hydroxyl radicals), and the applied current density. As an example, the authors simulated $\mathrm{HO}$ - concentration profile during oxidation of formic acid $(0.25-1 \mathrm{M})$ at $300 \mathrm{~A} \mathrm{~m}^{-2}$. It can be seen that the higher is the formic acid concentration, the lower is the surface concentration of $\mathrm{HO} \bullet$ and the smaller is the thickness of the reaction layer. For investigated concentrations of formic acid, the thickness of the reaction layer (reaction cage) drops down to barely tenths of nanometers, which is significantly lower as compared with that in the absence of organics. The comparison of $\mathrm{HO} \cdot$ concentration profile for $1 \mathrm{M}$ formic acid, methanol, and ethanol showed that depending on the rate constant; the thickness of the reaction layer varied between few nanometers and tenths of nanometers. ${ }^{46}$

These results have allowed to understand that the formation, reactivity and concentration profile play an important role during organic electrochemical oxidation; these factors are dependent on the nature of electrode material. Besides, the participation of molecular oxygen also to participation of hydroxyl radicals is changing some mechanisms assumptions and increasing the interest of electrochemists, as discussed below.

\section{MINERALIZATION OF ORGANICS BY MOLECULAR OXYGEN}

A recent report by two German and Swiss research groups has provided new evidences for organics EO on BDD anodes, supporting that the nature of anode material plays a key role in the electrocatalytic mechanism. ${ }^{45}$ Helmut Baltruschat (Universität Bonn, Germany), along with Christos Comninellis (Ecole Polytechnique Fédérale de Lausanne, Switzerland) and colleagues showed that organics mineralization on BDD electrodes does not only involve hydroxyl radicals but also molecular oxygen present in air/oxygen-saturated aqueous organic solutions. The direct evidence for this process was found during EO of an acetic acid (AA) solution saturated with isotopically labelled ${ }^{18} \mathrm{O}_{2}$ resulting in the formation of $\mathrm{C}^{18} \mathrm{O}_{2}$ and $\mathrm{C}^{16} \mathrm{O}^{18} \mathrm{O}$.

The underlying motivation was the understanding why ICE values on BDD were sometimes higher than $100 \%$, during organics EO (Figure 1). ${ }^{36}$ For that, they hypothesized a possible participation of dissolved oxygen. Therefore, they studied the electrochemical behavior of several aqueous solutions containing dissolved oxygen or not (aerated, ${ }^{16} \mathrm{O}_{2}$-saturated, and ${ }^{18} \mathrm{O}_{2}$-saturated, or deaerated by argon), in $1 \mathrm{M} \mathrm{HClO}_{4}$ with $50 \mathrm{mM} \mathrm{AA}$ at ambient temperature. Oxygen, ${ }^{16} \mathrm{O}_{2}$, or isotopically labelled oxygen, ${ }^{18} \mathrm{O}_{2}$, was bubbled in the solution during measurements in order to understand the participation of the oxygen dissolved in solution. During the organics EO voltammetric experiments, the $\mathrm{CO}_{2}$ evolution and $\mathrm{O}_{2}$ consumption were monitored by differential electrochemical mass spectrometry (DEMS). Based on the initial results obtained by cyclic voltammetry (CV) and mass spectrometric cyclic voltammetry (MSCV), the behaviors found by both techniques were very similar, allowing to conclude that neither the faradaic current nor the $\mathrm{C}^{16} \mathrm{O}_{2}$ evolution was influenced by dissolved oxygen in the solution. On the contrary, the ionic current associated to ${ }^{16} \mathrm{O}_{2}$ decreased in parallel with the $\mathrm{C}^{16} \mathrm{O}_{2}$ evolution, for both aerated and ${ }^{16} \mathrm{O}_{2}$-saturated solutions. The decrease of the ionic current associated to ${ }^{16} \mathrm{O}_{2}$ indicates that molecular oxygen dissolved in the solution could participate in AA oxidation. In order to verify this hypothesis, an experiment with ${ }^{18} \mathrm{O}_{2}$-saturated solution of AA was performed. In this context, during the experiment, in parallel with the decrease of ${ }^{18} \mathrm{O}_{2}$, an increase of the ionic current associated to ${ }^{16} \mathrm{O}^{18} \mathrm{O}$ (in ${ }^{18} \mathrm{O}_{2}$-saturated solution) was observed. Thus, this formation of ${ }^{16} \mathrm{O}^{18} \mathrm{O}$ indicated that intermediates involved in oxygen evolution (probably $\mathrm{HO}^{*}$ ) are regenerated during chain reactions.

Additional data obtained using isotopically labelled $\mathrm{C}^{18} \mathrm{O}_{2}$ and $\mathrm{C}^{18} \mathrm{O}^{16} \mathrm{O}$ demonstrated that these species are evolved in parallel with the ${ }^{18} \mathrm{O}_{2}$ decrease, confirming that oxygen dissolved in the solution is involved in AA oxidation. In this way, Comninellis, Baltruschat, and colleagues proposed an original and additional mechanism for the electrochemically induced oxidation of organic compounds via molecular oxygen dissolved in aerated solutions on BDD electrodes, as shown in Figure $2 .^{45}$

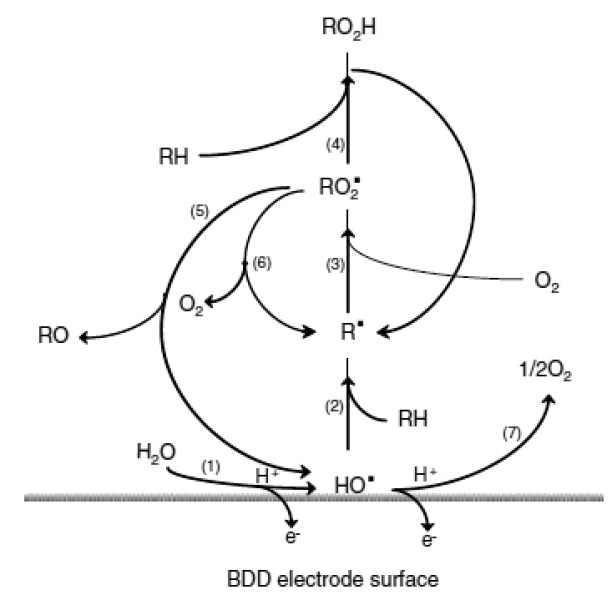

Figure 2. (1) Water discharge to hydroxyl radical HO; (2) dehydrogenation of organic compound $\mathrm{RH}$ via $\mathrm{HO}^{*}$ and formation of free organic radical $\mathrm{R}^{*}$; (3) addition of molecular oxygen to $R^{*}$ resulting in the formation of an organic peroxy radical $\mathrm{RO}_{2}{ }_{2}$; (4) dehydrogenation of $\mathrm{RH}$ via $\mathrm{RO}_{2}^{\cdot}$ resulting in the formation of hydroperoxide $\mathrm{ROOH}$ and regeneration of $R^{*}$; (5) decomposition of $\mathrm{RO}_{2}{ }_{2}$ leading to the regeneration of $\mathrm{HO}^{*}$ and formation of $\mathrm{RO}$; (6) decomposition of $\mathrm{RO}_{2}{ }_{2}$ to $\mathrm{R}^{*}$; (7) oxygen evolution, a side reaction. Reprinted of ref. 45, with permission from Elsevier

This activation of the reaction with molecular oxygen proceeds most likely through the sequence of reactions that are initiated by $\mathrm{HO}^{*}$ formed on the electrode surface. A similar mechanism of activation had been previously observed by radiolysis of hydrocarbons $(\mathrm{RH})$, when it was found that during the ionizing irradiation of an aqueous solution of organic compounds (with X or $\gamma$ rays), molecular oxygen enhances the oxidation processes. ${ }^{45}$ This occurs via addition of molecular oxygen to an organic free radical $\left(\mathrm{R}^{*}\right)$ resulting in the formation of an organic peroxy radical $\left(\mathrm{RO}_{2}{ }_{2}\right)$, which can participate in subsequent reactions. The organic free radical $\left(\mathrm{R}^{\circ}\right)$ is formed via the dehydrogenation of hydrocarbons ( $\mathrm{RH})$ initiated by $\mathrm{HO}^{*}$ formed during the radiolysis of water.

In conclusion, recent results obtained using simple molecules (carboxylic acids) support the view that hydroxyl radicals, molecular oxygen, and organic species affect the rate of organics mineralization. These findings lend further evidence to the importance of the nature of the electrode material and represent a new approach to the electrochemical oxidation mechanism. ${ }^{45-48}$ For this reason, these recent results open new avenues in the study of the EO mechanisms, so as to 
optimize such processes. Future developments will rely upon the close collaboration of electrochemists, engineers, and chemists to ensure the effective application and exploitation of EO techniques to control important water pollutants using the advances in electrocatalysis.

\section{NEW APPROACH FOR ELECTROCHEMICAL OXIDATION: GALVANOSTATIC CONDITIONS WITH THE POTENTIAL 'BUFFERED'}

Usually, electro-organic synthesis and destruction of organic pollutants oxidations process should be performed under potentiostatic conditions in order to achieve a high product selectively (in electrosynthesis) or for the complete destruction of organic matter with a high current efficiency (in the destruction of organic pollutants). However operation under potentiostatic conditions requires a reference electrode as well as a powerful potentiostat. Therefore, it is often problematic to work under potentiostatic conditions.

But recently, a new approach was proposed by Comninellis and co-workers ${ }^{49}$ in order to perform electrochemical oxidation of organics by working under galvanostatic conditions with the potential 'buffered' by the competing side reaction of OER. According to this process the working potential is fixed by the nature of electrode material and is buffered during organics oxidation by the side reaction of OER. Table 1 shows different anodes with their respective oxidation power, which is fixed by the oxygen evolution overpotential i.e., the higher the oxygen evolution overpotential the higher is the oxidation power of the anode. According Table 1, Ti//rO ${ }_{2}$ anodes have the lower oxidation power and BDD anodes have the higher oxidation power. This principle was used for the selective oxidation of secondary alcohols to the corresponding ketones and the oxidation of phenol to benzoquinone using $\mathrm{Ti} / \mathrm{IrO}_{2}$ anode.

In the case of phenol electrooxidation, the formation of hydroquinone, p-benzoquinone and pyrocatechol give the total aromatic selectivity, but current efficiency for the formation of all these products not exceeds $1 \%$. From these results, the authors have demonstrated two main futures: a) the fact that the total aromatic selectivity is close to one indicated that, at the working anodic potential (1.7 V) buffered by the side reaction of oxygen evolution on the $\mathrm{Ti} / \mathrm{IrO}_{2}$ anode, the oxidation products of phenol are stable toward further oxidation even after a quasi complete conversion of phenol. b) The high region selectivity toward benzoquinone formation (para to ortho ratio: 3 to 1) indicated that there was a specific orientation of phenol on the $\mathrm{IrO}_{2}$ surface during electrooxidation. In fact in absence of any interaction with the electrode, the main product is pyrocatechol (para to ortho ratio: 1 to 2).

According to the results reported by them,${ }^{49}$ a new approach can be considered in order to perform electrochemical oxidation of organics under pseudo-potentiostatic conditions, fixing the working potential by the nature of electrode material and it is buffered during organics oxidation by the side reaction of OER.

\section{DEDICATION}

This review is dedicated to Prof. C. Comninellis for his experimental and scientific work about the wastewater treatment, as well as for his recent scientific contribution concerning electrochemical oxidation mechanisms.

\section{ACKNOWLEDGEMENTS}

The authors are indebted to Prof. R. C. Rocha-Filho (Universidade Federal de São Carlos, Brazil) and Prof. A. De Battisti (University of Ferrara, Italy) for their very fruitful discussions.

\section{NOMENCLATURE}

BDD Boron doped diamond

COD Chemical oxygen demand

CV Cyclic voltammetry

DEMS Differential electrochemical mass spectrometry

DEO Direct electrochemical oxidation

EO Electrochemical oxidation

EOI Electrochemical oxidation index

ICE Instantaneous current efficiency

MEO Mediated electrochemical oxidation

MO Metal oxide

MSCV Mass spectrometric cyclic voltammetry

OER Oxygen evolution reaction

\section{REFERENCES}

1. Rajeshwar, K.; Ibanez, J. G.; Swain, G. M.; J. Appl. Electrochem. 1994, 24, 1077.

2. Rajeshwar, K.; Ibanez, J. G.; Environmental Electrochemistry: Fundamentals and Applications in Pollution Abatement, Academic Press: San Diego, 1997.

3. Martínez-Huitle, C. A.; Ferro, S.; Chem. Soc. Rev. 2006, 35, 1324.

4. Walsh, F.; Reade, G.; Analyst 1994, 119, 791.

5. Comninellis, C.; Electrochim. Acta 1994, 11-12, 1857.

6. Panizza, M.; Cerisola, G. In Advances in Chemistry Research; Zinger, D. V., ed.; Nova Science Publishers: New York, 2006, vol. 2.

7. Comninellis, C.; Kapalka, A.; Malato, S.; Parsons, S. A.; Poulios, I.; Mantzavinos, D.; J. Chem. Technol. Biotechnol. 2008, 83, 769.

8. Panizza, M.; Cerisola, G.; Chem. Rev. 2009, 109, 6541.

9. Brillas, E.; Sires, I.; Oturan, M. A.; Chem. Rev. 2009, 109, 6570.

10. Martinez-Huitle, C. A.; Brillas, E.; Appl. Catal., B 2009, 87, 105.

11. Andrade, L. S.; Ruotolo, L. M. M.; Rocha-Filho, R. C.; Bocchi, N.; Biaggio, S. R.; Iniesta, J.; García-García, V.; Montiel, V.; Chemosphere 2007, 66, 2035.

12. Awad, H. S.; Galwa, N. A.; Chemosphere 2005, 611327

13. Panizza, M.; Cerisola, G.; App. Catal., B 2007, 75, 95.

14. Chen, X.; Chen, G.; Yue, P. L.; Chem. Eng. Sci. 2003, 58, 995.

15. Chen, X.; Chen, G.; Gao, F.; Yue, P. L.; Environ. Sci. Technol. 2003, 37, 5021 .

16. Catanho, M.; Malpass, G. R. P.; Motheo, A. J.; Appl. Catal., B 2006, 62, 193.

17. Socha, A.; Sochocka, E.; Podsiadły, R.; Sokołowska, J.; Color. Technol. 2006, 122, 207

18. Hattori, S.; Doi, M.; Takahashi, E.; Kurosu, T.; Nara, M.; Nakamatsu, S.; Nishiki, Y.; Furuta, T.; Iida, M.; J. Appl. Electrochem. 2003, 33, 85.

19. López-Grimau, V.; Gutiérrez, M. C.; Chemosphere 2006, 62, 106.

20. Fan, L.; Zhou, Y.; Yang, W.; Chen, G.; Yang, F.; J. Hazard. Mater. 2006, 137,1182

21. Cameselle, C.; Pazos, M.; Sanromán, M. A.; Chemosphere 2005, 60, 1080.

22. Chen, X.; Gao, F.; Chen, G.; J. Appl. Electrochem. 2005, 35, 185.

23. Koparal, A. S.; Yavuz, Y.; Gürel, C.; Ö ütveren, Ü. B.; J. Hazard. Mater. 2007, 145, 100 .

24. Hastie, J.; Bejan, D.; Teutli-León, M.; Bunce, N. J.; Ind. Eng. Chem. Res. 2006, 45, 4898

25. Bechtold, T.; Turcanu, A.; Schrott, W.; Diamond Relat. Mater. 2006, 15, 1513.

26. Cañizares, P.; Gadri, A.; Lobato, J.; Nasr, B.; Paz, R.; Rodrigo, M. A.; Saez, C.; Ind. Eng. Chem. Res. 2006, 45, 3468.

27. Panizza, M.; Cerisola, G.; J. Hazard. Mater. 2007, 153, 83.

28. Costa, C. R.; Montilla, F.; Morallón, E.; Olivi, P.; Electrochim. Acta 2009, 54, 7048 . 
29. Montanaro, D.; Petrucci, E.; Chem. Eng. J. 2009, 153, 138.

30. Lopes, A.; Martins, S.; Morao, A.; Magrinho, M.; Goncalves, I.; Port. Electrochim. Acta 2004, 22, 279.

31. Dávila-Jiménez, M. M.; Elizalde-González, M. P.; Gutiérrez-González, A.; Peláez-Cid, A. A.; J. Chromatogr., A 2000, 889, 253.

32. Szpyrkowicz, L.; Radaelli, M.; Daniele, S.; Baldacci, A.; Kau, S.; Ind. Eng. Chem. Res. 2007, 46, 6732.

33. Feng, J.; Johnson, D. C.; J. Electrochem. Soc. 1990, 137, 507.

34. Marselli, B.; Garcia-Gomez, J.; Michaud, P. A.; Rodrigo, M. A.; Comninellis, C.; J. Electrochem. Soc. 2003, 150, D79.

35. Panizza, M.; Michaud, P. A.; Cerisola, G.; Comninellis, C.; J. Electroanal. Chem. 2001, 507, 206.

36. Kapałka, A.; Fóti, G.; Comninellis, C.; J. Appl. Electrochem. 2008, 38, 7.

37. Polcaro, A. M.; Vacca, A.; Palmas, S.; Mascia, M.; J. Appl. Electrochem. 2003, 33, 885 .

38. Cañizares, P.; Diaz, M.; Dominguez, J. A.; Garcia-Gomez, J.; Rodrigo, M. A.; Ind. Eng. Chem. Res. 2002, 41, 4187.

39. Cañizares, P.; Garcia-Gomez, J.; Lobato, J.; Rodrigo, M. A.; Ind. Eng. Chem. Res. 2004, 43, 1915.
40. Cañizares, P.; Garcia-Gomez, J.; Lobato, J.; Rodrigo, M. A.; Ind. Eng. Chem. Res. 2004, 43, 1923.

41. Scialdone, O.; Electrochim. Acta 2009, 54, 6140.

42. Scialdone, O.; Randazzo, S.; Galia, A.; Filardo, G.; Electrochim. Acta 2009, 54, 1210 .

43. Scialdone, O.; Galia, A.; Guarisco, C.; Randazzo, S.; Filardo, G.; Electrochim. Acta 2008, 53, 2095.

44. Scialdone, O.; Randazzo, S.; Galia, A.; Silvestri, G.; Water Res. 2009, 43,2260

45. Kapałka, A.; Lanova, B.; Baltruschat, H.; Fóti, G.; Comninellis, C.; Electrochem. Commun. 2008, 10, 1215.

46. Kapałka, A.; Fóti, G.; Comninellis, C.; Electrochim. Acta 2009, 52, 2018.

47. Andrade, L. S.; Thasso, T. T.; Silva, D. L.; Rocha-Filho, R. C.; Bocchi, N.; Biaggio, S. R.; Electrochim. Acta 2009, 54, 2024.

48. Andrade, L. S.; Rocha-Filho, R. C.; Bocchi, N. Biaggio, S. R.; Iniesta, J.; García-García, V.; Montiel, V.; J. Hazard. Mater. 2008, 153, 252.

49. Fierro, S.; Passas-Lagos, E.; Chatzisymeon, E.; Mantzavinos, D.; Comninellis, Ch.; Electrochem. Commun. 2009, 11, 1358. 